\title{
Transcatheter aortic valve implantation complicated by papillary muscle rupture with a good final outcome
}

\author{
Danuta Sorysz ${ }^{1}$, Andrzej Gackowski ${ }^{2,3}$, Jarosław Trębacz ${ }^{2}$, Artur Dziewierz ${ }^{1,4}$, Andrzej Surdacki ${ }^{1,4}$, \\ Stanisław Bartuś ${ }^{1,4}$, Dariusz Dudek ${ }^{1,4}$ \\ ${ }^{1}$ Department of Cardiology and Cardiovascular Intervention, University Hospital, Krakow, Poland \\ ${ }^{2}$ Department of Cardiovascular Interventions, John Paul II Hospital, Krakow, Poland \\ ${ }^{3}$ Department of Coronary Disease and Heart Failure, Noninvasive Cardiovascular Lab, John Paul II Hospital, Krakow, Poland \\ ${ }^{4} 2^{\text {nd }}$ Department of Cardiology, Jagiellonian University Medical College, Krakow, Poland
}

Adv Interv Cardiol 2021; 17, 2 (64): 232-233

DOI: https://doi.org/10.5114/aic.2021.107510

An 88-year-old patient with a history of coronary artery bypass grafting was referred for transfemoral transcatheter aortic valve implantation (TAVI) because of severe, symptomatic (NYHA III) aortic stenosis with coexisting renal failure and other comorbidities. In echocardiogram, a severely calcified 3-cuspid aortic valve with an aortic valve area of $0.6 \mathrm{~cm}^{2}$ was noted (aortic maximal pressure gradient of $90 \mathrm{~mm} \mathrm{Hg}$ and mean gradient of $46 \mathrm{~mm} \mathrm{Hg}$ ). The left ventricle (LV) had a small cavity and was concentrically hypertrophied (LVEDD $42 \mathrm{~mm}$, IVSd 15 mm, LVEF 60\%). The mitral annulus was moderately calcified. There was mild mitral regurgitation without significant stenosis (mean gradient $3.2 \mathrm{~mm} \mathrm{Hg}$, MVA $2.5 \mathrm{~cm}^{2}$ ). In computed tomography the aortic annulus area was $5.6 \mathrm{~cm}^{2}$. Revascularization was not required.

Because of the high risk of surgery, the patient was scheduled for transfemoral TAVI (Euroscore II 6.1\%, logistic Euroscore $35.7 \%$, STS 5.8\%).

During the procedure, the wire was properly inserted into the LV apex. Successful balloon aortic valvuloplasty was performed. However, during the implantation of an Edwards Sapien XT 29 mm valve, sudden migration of the balloon towards the LV was observed (Figure $1 \mathrm{~A}$ ). Due to the underexpansion of the valve, postdilatation was necessary. However, during the inflation, the balloon moved slightly towards the LV again. It was immediately deflated, repositioned, and finally the valve was expanded at a low position. Post-procedural routine transoesophageal echocardiography showed good valve function with a mild perivalvular leak. However, a rupture of the papillary muscle was found (Figure $1 \mathrm{~B}$ ). The papillary muscle was freely swinging between LV and LA and was attached to the chordae tendineae of the A3 mitral segment. Unexpectedly, only moderate mitral regurgitation (Figure $1 \mathrm{C}$ ) was observed (VC $3 \mathrm{~mm}$, EROA $0.15 \mathrm{~cm}^{2}$, RV $20 \mathrm{ml}$ ). A conservative approach was chosen because the patient was at high risk of surgery and remained stable during $30 \mathrm{~min}$ of observation. No other complications were observed. Control echocardiography did not show aggravation of mitral regurgitation (Figure $1 \mathrm{D}$ ). The patient was discharged home on the $4^{\text {th }}$ day. Three and 12 months later, echocardiographic and clinical status did not worsen (NYHA III class). Only LV cavity enlargement was observed (LVEDd from $42 \mathrm{~mm}$ to $52 \mathrm{~mm}$ ). Deterioration of the symptoms (NYHA III/IV and dementia) was observed 2 years after TAVI (phone visit). It was the last contact with the patient.

Papillary muscle rupture is a very rarely reported but potentially catastrophic complication of TAVI. Migration of the large balloon to the small hypertrophic LV can damage the mitral apparatus.

Such a complication could have 2 mechanisms. The first may occur when the guidewire crosses between the chords of the mitral apparatus and the rapid balloon's inflation pulls the papillary muscle. However, in this situation, the passage of the guidewire through the mitral subvalvular apparatus increases mitral regurgitation, which was not observed. The second is mechanical damage of the muscle by the balloon nosecone moved into the LV. It may occur especially in a small, hypertrophic cavity, like in our patient.

Papillary muscle rupture usually causes severe consequences, but because of the narrow, calcified mitral annulus and only partial muscle rupture, the mitral regurgi-

\section{Corresponding author:}

Danuta Sorysz MD, PhD, Institute of Cardiology, Medical College Jagiellonian University, University Hospital, Krakow, Poland, phone: +48602 227 786, e-mail: dtsorysz@op.pl

Received: 12.04.2021, accepted: 15.05.2021. 


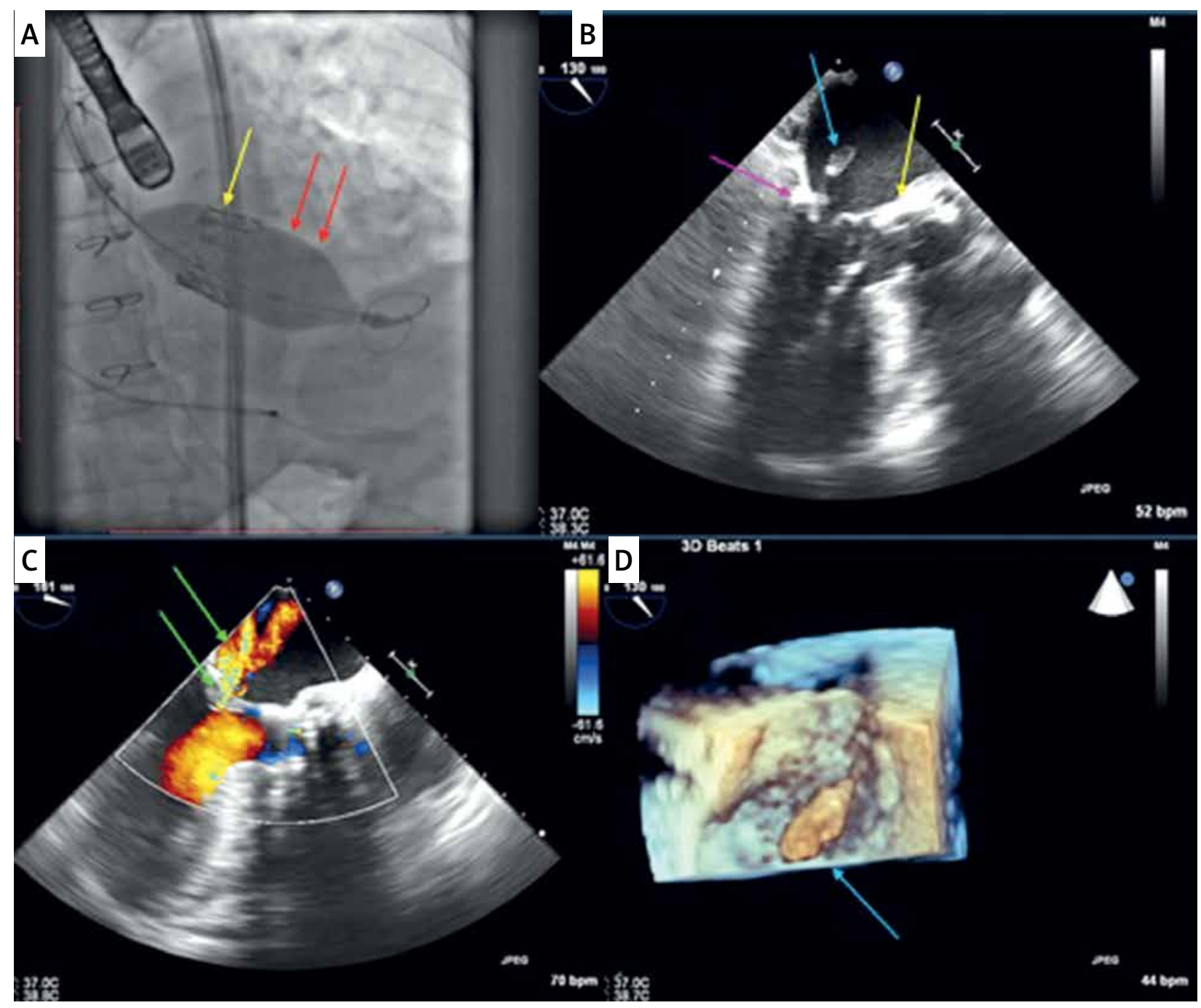

Figure 1. - A Fluoroscopy: implantation of TAVI valve (yellow arrow): views of the balloon displaced into the LV (red arrow) and under-expanded valve. B - TEE: ruptured papillary muscle visible in systole in the left atrium (blue arrow - head of the ruptured papillary muscle, violet arrow - calcification of the mitral annulus, yellow arrow - TAVI valve). C - TEE: colour Doppler showing moderate (narrow vena contracta) mitral regurgitation (green arrow - colour Doppler of mitral regurgitation). D - 3D TEE: ruptured papillary muscle visible in systole in the left atrium (blue arrow - head of the ruptured papillary muscle)

tation may be moderate and in selected patients treated conservatively [1-4].

\section{Conflict of interest}

The authors declare no conflict of interest.

\section{References}

1. De la Torre Hernandez JM, Gorria GM, de Prada JA, Zueco J. Papillary muscle rupture: first report of this complication in a retrograde transfemoral aortic valve implantation. Catheter Cardiovasc Interv 2011; 78: 647-9.
2. Goel SS, Zuck V, Nallamothu N, Goswami NJ. Successful MitraClip for severe mitral regurgitation secondary to papillary muscle rupture as a complication of transcatheter aortic valve replacement. JACC Cardiovasc Interv 2018; 11: e47-8.

3. Sasaki K, Watanabe Y, Kataoka A, Kozuma K. Papillary muscle rupture during transcatheter aortic valve replacement. Cardiovasc Interv Ther 2021; 36: 134-5.

4. Morita Y, Endo A, Tanabe K. Papillary muscle rupture after transcatheter aortic valve implantation. Catheter Cardiovasc Interv 2020 Sep 23 [Epub ahead of print]; doi: 10.1002/ccd.29252. 